\title{
Nitric Oxide as an Endogenous Peripheral Modulator of Visceral Sensory Neuronal Function
}

\author{
Amanda J. Page, ${ }^{1,2,3}$ Tracey A. O'Donnell, ${ }^{1}$ Nicole J. Cooper, ${ }^{1}$ Richard L. Young ${ }^{1,2}$ and L. Ashley Blackshaw ${ }^{1,2,3}$ \\ ${ }^{1}$ Nerve-Gut Research Laboratory, Hanson Institute, Royal Adelaide Hospital, Adelaide, South Australia 5000, Australia, and Disciplines of ${ }^{2}$ Medicine and \\ ${ }^{3}$ Physiology, School of Molecular and Biomedical Sciences, University of Adelaide, Adelaide, South Australia 5000, Australia
}

Nitric oxide (NO) plays important roles in CNS and smooth muscle function. Here we reveal an additional function in peripheral sensory transmission. We hypothesized that endogenous NO modulates the function of gastrointestinal vagal afferent endings. The nonselective NO synthase (NOS) inhibitor $N^{\mathrm{G}}$-nitro-L-arginine methyl ester hydrochloride increased responses to tactile mechanical stimuli of mucosal afferent endings in two species, in some cases severalfold. This was mimicked by a neuronal NOS inhibitor but not an endothelial NOS inhibitor. NOS inhibitors did not affect the responsiveness of smooth muscle afferent endings, suggesting that the endogenous source of NO is exclusively accessible to mucosal receptors. The role of the NO-soluble guanylyl cyclase (sGC)-cGMP pathway was confirmed using the sGC inhibitor $1 H$-[1,2,4] oxadiazolo[4,3-a]quinoxaline-1-one and the cGMP phosphodiesterase 5' inhibitor sildenafil. The first enhanced and the second inhibited mechanosensory function. Exogenous NO, from the donor $S$-nitroso- $N$ acetylpenicillamine, significantly reduced mechanosensitivity of both types of ending. Up to one-third of stomach-projecting afferent neurons in the nodose ganglia expressed neuronal NOS (nNOS). However, anterograde-traced vagal endings were nNOS negative, indicating NOS is not transported peripherally and there are alternative sources of NO for afferent modulation. A subpopulation of enteroendocrine cells in the gut mucosa were nNOS positive, which were found anatomically in close apposition with mucosal vagal afferent endings. These results indicate an inhibitory neuromodulatory role of epithelial NO, which targets a select population of vagal afferents. This interaction is likely to play a role in generation of symptoms and behaviors from the upper gastrointestinal system.

\section{Introduction}

Since the identification of nitric oxide (NO) as an endotheliumderived relaxing factor (Furchgott and Zawadzki, 1980; Palmer et al., 1987), it has been shown to be involved in a range of physiological processes (Moncada, 1992), including a role as a messenger molecule within the CNS and peripheral nervous system (Garthwaite et al., 1988; Bredt and Snyder, 1992; Garthwaite and Boulton, 1995). NO is synthesized from L-arginine by NO synthase (NOS), of which there are three isoforms: neuronal NOS (nNOS), inducible NOS (iNOS), and endothelial NOS (eNOS) (Alderton et al., 2001). The two types of constitutive NOS, nNOS and eNOS, participate in normal physiological responses, whereas iNOS, not usually present in tissues, is induced during injury and inflammation (Xie et al., 1992).

The role of NO in peripheral sensory signaling is currently obscure. Interfering with NO production increases articular C-fiber activity (Kelly et al., 2001), but exogenous NO can increase or decrease mechanosensitivity of somatic nociceptors (Vivancos et al., 2003; Levy and Strassman, 2004). NO decreases soma excitability of vagal sensory neurons (Bielefeldt et al., 1999). Inhibition of visceral afferents is an important therapeutic target

Received Dec. 21, 2008; revised March 29, 2009; accepted April 22, 2009

This work was supported by a National Health and Medical Research Council Senior Research Fellowship to L.A.B. and by Astra Zeneca.

Correspondence should be addressed to Amanda J. Page, Nerve-Gut Research Laboratory, Room 1-216-H, Level 1, Hanson Institute, Frome Road, Adelaide, SA 5000, Australia. E-mail: amanda.page@health.sa.gov.au. DOI:10.1523/JNEUROSCI.6099-08.2009

Copyright @ 2009 Society for Neuroscience $\quad 0270-6474 / 09 / 297246-10 \$ 15.00 / 0$ in several gastrointestinal diseases. Functional dyspepsia is characterized by increased perception of gastric stimuli (Tack et al., 2004). Nausea and vomiting are linked to activation of vagal afferents (Andrews and Sanger, 2002; Blackshaw and Gebhart, 2002). Eating disorders are associated with abnormal responses to luminal contact with a meal (Robinson et al., 1988), and may involve altered nitrergic function (Morley et al., 1995).

Possible sources of $\mathrm{NO}$ within the gastrointestinal tract are numerous. It has been demonstrated that NO is a inhibitory nonadrenergic noncholinergic neurotransmitter and NO release causes relaxation of gastrointestinal smooth muscle (Bult et al., 1990; Boeckxstaens et al., 1991; D’Amato et al., 1992). NO is also released from the myenteric plexus, where it is synthesized by nNOS in myenteric neurons (Bredt et al., 1990). Sensory nerves are another credible source of $\mathrm{NO}$ with both nNOS and eNOS being present within vagal afferent cell bodies (Yamamoto et al., 2003). In addition to neuronal sources of NO a variety of cells in the gastric epithelium can also produce NO (García-Vitoria et al., 2000). The epithelial-to-neuronal communication process is very important in many areas of the body, including the bladder (Birder, 2005) and the gastrointestinal tract, and as such, the gastric epithelium is a rich source of NO. Various specialized cells within the gastric mucosa have been found to contain nNOS, including brush cells (Kugler et al., 1994), chief cells (Fiorucci et al., 1995), and some endocrine cells (Burrell et al., 1996) and mucosecretory cells (Brown et al., 1992; Price et al., 1996; Byrne et al., 1997; Ichikawa et al., 1998; Price and Hanson, 1998).

We have developed methods that enable evaluation of the 
modulatory effect of endogenous and exogenous compounds on mechanosensitivity of vagal afferents innervating the gastrointestinal tract (Page and Blackshaw, 1998; Page et al., 2002). Using these preparations, we have shown that GABA and glutamate are coupled to inhibition of afferent mechanosensitivity (Page and Blackshaw, 1999; Page et al., 2005b), effects that translate to changes in gastrointestinal function in vivo (Blackshaw, 2001; Zhang et al., 2002). We considered the possibility that NO may have peripheral actions on sensory neurons, which may be important in modulation of visceral sensation and reflex control of gastrointestinal function. The aims of this study were to determine the effect of NO on mechanosensitivity of gastroesophageal vagal afferents and the source of endogenous NO. We also sought to determine the mechanism of action by which NO elicits its effect.

\section{Materials and Methods}

All experimental studies were performed with the approval of the animal ethics committee of the Institute of Medical and Veterinary Science and the University of Adelaide, and in accordance with the Australian Code of Practice for the Care and Use of Animals for Scientific Purposes.

\section{In vitro mouse gastroesophageal afferent preparation}

C57BL/6 mice fed ad libitum (20-30 g) were humanely killed via $\mathrm{CO}_{2}$ inhalation, and the thorax was opened by a midline incision. The stomach and esophagus with attached vagal nerves were removed and placed in a modified Krebs' solution containing the following (in $\mathrm{mM}$ ): 118.1 $\mathrm{NaCl}, 4.7 \mathrm{KCl}, 25.1 \mathrm{NaHCO}_{3}, 1.3 \mathrm{NaH}_{2} \mathrm{PO}_{4}, 1.2 \mathrm{MgSO}_{4} \cdot 7 \mathrm{H}_{2} \mathrm{O}, 1.5$ $\mathrm{CaCl}_{2}, 1.0$ citric acid, and 11.1 glucose, bubbled with $95 \% \mathrm{O}_{2}-5 \% \mathrm{CO}_{2}$ at $4^{\circ} \mathrm{C}$ during dissection to prevent metabolic degradation. After further dissection, the preparation was opened out longitudinally along the esophagus and greater curve of the stomach. The preparation was then placed mucosal side up in the organ bath. This preparation has been described in detail previously (Page et al., 2002, 2005a). Nifedipine (1 $\mu \mathrm{M}$ ) was also added to the Krebs' solution to prevent smooth muscle contraction. In a previous preliminary study, we have shown that nifedipine has no effect on the mechanical sensitivity of gastroesophageal vagal afferents (Page et al., 2006).

\section{In vitro ferret gastroesophageal afferent preparation}

Ferrets (0.5-1.0 kg body weight) were deeply anesthetized with sodium pentobarbitone $\left(60 \mathrm{mg} \cdot \mathrm{kg}^{-1}\right.$, i.p. $)$, and the thorax was opened by a midline incision. The ferret was killed by exsanguination under anesthesia. The stomach and esophagus were then placed in an organ bath in a similar manner to the mouse preparation. This preparation has already been described in detail previously (Page and Blackshaw, 1998).

\section{Characterization of gastroesophageal vagal afferent properties}

In the ferret, three distinct types of afferent fiber were recorded: those responding to circular tension but not to low-intensity mucosal stimuli (tension receptors), those responding only to mucosal stroking (mucosal receptors), and those responding to both mucosal stroking and circular tension [tension/mucosal receptors (Page and Blackshaw, 1998, 1999)]. In the mouse, two types of mechanosensitive afferent fiber were studied, those responding to mucosal stroking but not circular tension (mucosal receptors) and those responding to mucosal stroking and circular tension (tension receptors) as reported previously (Page et al., 2002).

Location of receptive fields of all types of afferent fiber was determined by mechanical stimulation throughout the preparation with a brush. Accurate quantification of mechanical responses was performed differently according to the primary adequate stimulus for the type of fiber. Mechanical thresholds of both types of fiber were determined using calibrated von Frey hairs. The most reproducible, stimulus-dependent responses of these afferents to mucosal stroking were evoked when the probe was moved at a rate of $5 \mathrm{~mm} \cdot \mathrm{s}^{-1}$ across the receptive field rather than being kept static. Due to the fact that the receptive fields were small $\left(<1 \mathrm{~mm}^{2}\right)$, a single test at each intensity is prone to missing the center of the receptive field on some occasions. Therefore, we minimized experimenter error by measuring the mean response to the middle 8 of 10 standard strokes given at $1 \mathrm{~s}$ intervals. Because the von Frey hair was bent throughout the stroking stimulus, the receptive field was subjected to an even force as the hair passed over it. Tension-response curves were also obtained for all afferent fibers, which were used in combination with von Frey thresholds to determine whether the receptive fields of fibers were located in the mucosa or the muscle layer. Tension stimuli were applied via fine suture silk attached to an unpinned point adjacent to the mechanoreceptive fields. The thread was attached to a cantilever via a pulley close to the preparation. Reference standard weights were then placed on the opposite end of the cantilever. Each weight was applied as a step and maintained for $1 \mathrm{~min}$, and the response was measured as the mean discharge evoked over this period. Due to the fact that all responses to tension adapted slowly, this method of assessment was considered representative of physiological responsiveness. The tension-response curves were produced by applying weights to the cantilever system in the range of 1-5 g. A recovery period of at least $1 \mathrm{~min}$ was allowed between each tension stimulus.

\section{Effect of the nonselective nitric oxide synthase inhibitor L- NAME on the mechanosensitivity of vagal afferents}

After mechanical sensitivity of the gastroesophageal vagal afferent had been established, the effect of the nonselective NOS inhibitor $N^{\mathrm{G}}$-nitroL-arginine methyl ester hydrochloride (L-NAME) on mechanical sensitivity was determined. L-NAME $(0.1 \mathrm{~mm})$ was added to the superfusing solution and allowed to equilibrate for $20 \mathrm{~min}$, after which time the tension-response and stroke-response curves were redetermined. This equilibration period was observed so as to ensure penetration of the drug into all layers of the tissue. If L-NAME had an effect on the mechanical sensitivity of the vagal afferent, then $\mathrm{L}$-arginine $(0.1 \mathrm{mM})$ was added to the superfusing solution along with L-NAME $(0.1 \mathrm{mM})$ to determine whether the effect of L-NAME could be reversed. The preparation was allowed to equilibrate for a further $20 \mathrm{~min}$, after which time the mechanosensitivity of the vagal afferent was redetermined. Time-controlled experiments were performed in which there was no significant change in the mechanical responses over a comparable duration.

\section{Effect of the selective nitric oxide synthase inhibitors L-NIO and $N$-PLA on the mechanosensitivity of vagal afferents}

After mechanical sensitivity of the gastroesophageal vagal afferent had been established, the effect of the eNOS inhibitor, $N^{5}$-(1-iminoethyl)-Lornithine dihydrochloride (L-NIO; $1 \mu \mathrm{M}$ ), or the nNOS inhibitor, $N^{\omega_{-}}$ propyl-L-arginine ( $N$-PLA; $0.1 \mu \mathrm{M}$ ) on mechanical sensitivity was determined. L-NIO or N-PLA was added to the superfusing solution and allowed to equilibrate for $20 \mathrm{~min}$, after which time the tension-response and stroke-response curves were redetermined. This procedure was repeated for L-NIO $(1-10 \mu \mathrm{M})$ or N-PLA $(0.1-1 \mu \mathrm{M})$ at increasingly higher doses. The concentrations of L-NIO and N-PLA used were based on previous in vitro pharmacological experiments reported in the literature (Gumusel et al., 1998; Fornai et al., 2007a,b). Time-controlled experiments were performed in which there was no significant change in the mechanical responses over a comparable duration (supplemental Fig. 1, available at www.jneurosci.org as supplemental material).

\section{Effect of the nitric oxide donor SNAP on the mechanosensitivity of vagal afferents}

After mechanical sensitivity of the gastroesophageal vagal afferent had been established, the effect of the NO donor $S$-nitroso- $N$ acetylpenicillamine (SNAP) on mechanosensitivity was determined. SNAP $(3 \mu \mathrm{M})$ was added to the superfusing solution and allowed to equilibrate for $20 \mathrm{~min}$, after which time the tension-response and stroke-response curves were redetermined. This procedure was repeated for SNAP at increasingly higher doses $(10-30 \mu \mathrm{M})$. 
Effect of the phosphodiesterase 5' inhibitor sildenafil on the mechanosensitivity of vagal afferents Sildenafil (10 nM) was added to the superfusing solution and allowed to equilibrate for $20 \mathrm{~min}$. Stroke-response curves were determined before and after sildenafil. This procedure was repeated for sildenafil at increasingly higher doses (30-100 nм). Time-controlled experiments were performed in which there was no significant change in the mechanical responses over a comparable duration.

\section{Effect of the NO-sensitive guanylyl cyclase inhibitor ODQ on the mechanosensitivity of vagal afferents} Stroke-response curves were determined before and $20 \mathrm{~min}$ after adding $1 \mathrm{H}$-[1,2,4] oxadiazolo[4,3-a] quinoxaline-1-one (ODQ; $1 \mu \mathrm{M}$ ) to the superfusing solution. This procedure was repeated for ODQ at increasingly higher doses $(3-10 \mu \mathrm{M})$.

\section{Data recording and analysis}

Afferent impulses were amplified with a biological amplifier (DAM 50; World Precision Instruments), filtered (bandpass filter-932; CWE), and monitored using an oscilloscope (DL 1200 A; Yokogawa). Single units were discriminated on the basis of action potential shape, duration, and amplitude using Spike 2 software (Cambridge Electronic Design). All data were recorded and analyzed off-line using a personal computer (IBM ThinkPad). Data are expressed as means \pm SEM, with $n$ equal to the number of individual afferents in all instances. The pharmacological protocol was performed on a maximum of one afferent fiber in each preparation. Differences between stimulus-response curves were evaluated using two-way ANOVA (Prism 3.02; Graphpad). Differences were considered significant if $p<0.05$.

\section{Drugs}

Stock solutions of all drugs were kept frozen and diluted to their final concentration in Krebs' solution on the day of the experiment. L-NAME, L-NIO, N-PLA, ODQ, and SNAP were obtained from Tocris Cookson. Sildenafil was obtained from the Royal Adelaide Hospital Pharmacy (Adelaide, Australia).

\section{Tracing studies}

Adult (20-40 g) male C57BL/6 mice had ad libitum access to water and a standard diet and were fasted overnight before experimentation.

\section{Retrograde tracing}

Gastric muscle. Mice $(n=5)$ were anesthetized with isoflurane $(2 \%$ in oxygen), a laparotomy performed, and an Alexa Fluor 555 conjugate of cholera toxin B-subunit (CTB-AF555 (0.5\%); Invitrogen) was injected subserosally into the columnar epithelium of the proximal stomach using a 33 ga Hamilton syringe. Multiple equally spaced injections of $1-2 \mu \mathrm{l}$ were made parallel to and 1-2 $\mathrm{mm}$ from the less curvature on both anterior and posterior surfaces (total volume $10 \mu \mathrm{l}$ ). The injection sites were dried, the laparotomy incision was closed, and antibiotic (Terramycin; $10 \mathrm{mg} / \mathrm{kg}$ ) and analgesic (butorphanol; $5 \mathrm{mg} / \mathrm{kg}$ ) were administered subcutaneously.

Gastric mucosa. Separate mice $(n=3)$ were anesthetized with isoflurane, a laparotomy performed and a mucolytic (10\% $\mathrm{N}$-acetylcysteine; $200 \mu \mathrm{l})$ injected into the stomach lumen, then removed via syringe after $5 \mathrm{~min}$, followed by two saline rinses (200 $\mu \mathrm{l} \mathrm{each).} \mathrm{Then,} 10 \mu \mathrm{l}$ of $0.5 \%$
CTB-AF555 was applied onto the posterior proximal wall mucosal via a 33 ga Hamilton syringe and the proximal stomach walls gently apposed for $5 \mathrm{~min}$ to equally expose the dorsal and ventral surfaces to tracer. The laparotomy incision was then closed and antibiotic and analgesic administered as above. Food and water were withheld for $2 \mathrm{~h}$ postoperatively in these mice to maximize exposure of tracer. All mice recovered well from surgery and were routinely monitored. Control experiments for detecting tracer spread were also performed in two separate mice, by assessment of tracer distribution in transverse sections of the whole stomach at $2 \mathrm{~h}$ after administration of tracer.

After $2 \mathrm{~d}$, traced mice were anesthetized with pentobarbitone $(60 \mathrm{mg} /$ $\mathrm{kg}$, i.p.) and transcardially perfused with heparinized saline at $40^{\circ} \mathrm{C}$, then $4 \%$ paraformaldehyde in $0.1 \mathrm{M}$ PBS (PFA-PBS) at $4^{\circ} \mathrm{C}$. The nodose ganglia were then removed and fixed in $4 \%$ PFA-PBS at room temperature for $2 \mathrm{~h}$ and then cryoprotected in $30 \%$ sucrose at $4^{\circ} \mathrm{C}$ for $24 \mathrm{~h}$. Frozen serial transverse sections $\left(\begin{array}{lll}10 & \mu \mathrm{M}\end{array}\right)$ were then cut for immunohistochemistry.

\section{Anterograde tracing}

Adult male mice $(n=5)$ were anesthetized with isoflurane ( $2 \%$ in oxygen). The left nodose ganglia was exposed, and $1 \mu \mathrm{l}$ of a horseradish peroxidase conjugate of wheat-germ agglutinin [WGA-HRP (4 $\mathrm{mg} \cdot \mathrm{ml}^{-1}$ ); Vector Laboratories] was pressure injected into the nodose ganglia via a glass micropipette (ID $=25 \mu \mathrm{m}$ ). The injection site was then dried, the skin incision closed, and antibiotic and analgesic administered as above. All mice recovered well from surgery and were routinely monitored. Two days following injection, mice were anesthetized and perfused as above. The stomach was removed and dissected in PBS into anterior and posterior flat sheets along the greater and lesser curvature. The submucosa and mucosa were gently removed leaving the smooth 


\section{Mouse gastroesophageal vagal afferents}

A) Mucosal

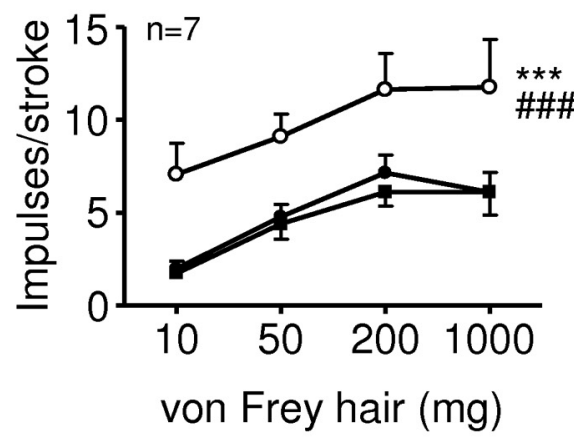

C) Mucosal

(i) Control

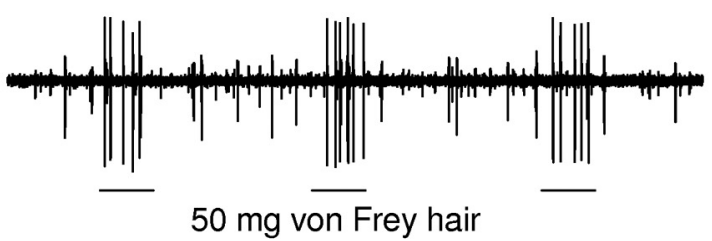

(ii) L-NAME $(100 \mu \mathrm{M})$

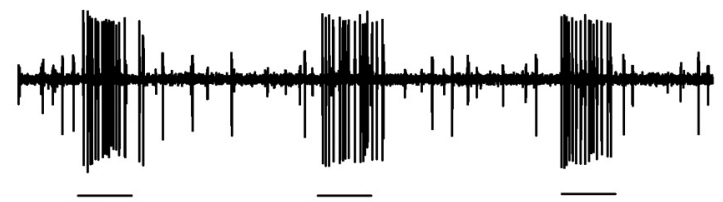

$50 \mathrm{mg}$ von Frey hair

(iii) L-NAME $(100 \mu \mathrm{M}) \&$ L-arginine $(100 \mu \mathrm{M})$

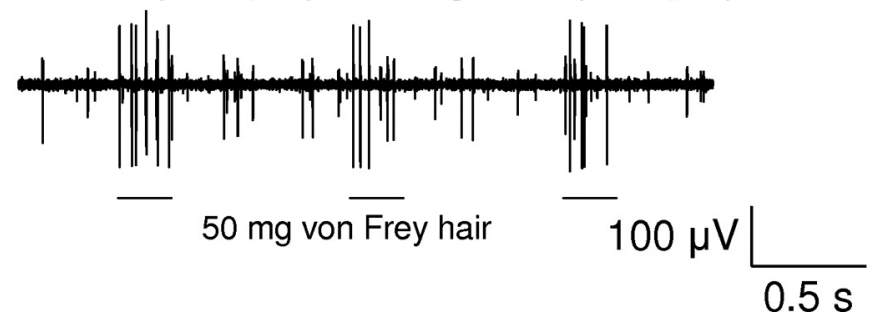

Figure 2. L-NAME potentiates mouse gastroesophageal vagal afferents. $\boldsymbol{A}, \boldsymbol{B}$, Stimulus-response functions of mucosal $(\boldsymbol{A})$ and tension $(\boldsymbol{B})$ receptors to mucosal stroking with calibrated von Frey hairs and circumferential tension, respectively. The responses are before $(\mathbf{O})$ and after $(\bigcirc)$ exposure to L-NAME $(100 \mu \mathrm{M})$ and L-NAME along with L-arginine $(100 \mu \mathrm{m} ; \mathbf{\square})$. ${ }^{* * *}$ Significant difference from control curve using a two-way ANOVA $(p<0.001)$. "\#\#"Significant difference of data obtained in the presence of L-NAME alone from data obtained in the presence of L-NAME and L-arginine using a two-way ANOVA ( $p<0.001)$. C, Original recording of a mucosal receptor to mucosal stroking with a $50 \mathrm{mg}$ calibrated von Frey hair in the absence $(\boldsymbol{i})$ and presence of L-NAME (ii) and L-NAME along with L-arginine (iii).

muscle layers and myenteric plexus intact. Permanent visualization of WGA-HRP was done using tyramide signal amplification (TSA). Briefly, whole mounts were rinsed in TNT buffer $(0.05 \%$ Tween $20,0.15 \mathrm{M} \mathrm{NaCl}$, and $0.1 \mathrm{M}$ Tris- $\mathrm{HCl}, \mathrm{pH} 7.5$ ), blocked for $30 \mathrm{~min}$ in TNB (prepared as per the directions provided with the Perkin-Elmer TSA biotin reagent kit), and then reacted for 20 min with tyramide-biotin, diluted 1:50 in amplification diluent. The tissue was then rinsed in TNT buffer and reacted with streptavidin conjugated to Alexa Fluor 546 (Invitrogen) for $2 \mathrm{~h}$ at room temperature. Following nNOS immunoreactivity (below) specimens were mounted on slides and coverslipped using ProLong antifade (Invitrogen) as the mounting medium.
Immunohistochemistry

Immunoreactivity for nNOS was detected in retrograde-traced nodose ganglia sections and anterograde-traced stomach and esophageal sections and stomach whole mounts using a rabbit anti-rat nNOS polyclonal antibody (617000; Invitrogen). Primary antibody was visualized by a goat anti-rabbit secondary antibody conjugated to Alexa Fluor 488 (Invitrogen). Briefly, sections were air dried at room temperature and rinsed in PBS $+0.2 \%$ Triton X-100 (Sigma-Aldrich; PBS-T, pH 7.4) to facilitate antibody penetration. Primary antibody was diluted 1:500 in PBS-T and incubated at $4^{\circ} \mathrm{C}$ overnight for sections, or for $48 \mathrm{~h}$ for stomach whole mounts; unbound antibody was then removed with PBS-T washes, and slides plus whole mounts were incubated for $1-2 \mathrm{~h}$ at room temperature with secondary antibody (1:200 in PBS-T). The tissue was given final PBS-T washes, drained, and mounted with ProLong Antifade (Invitrogen). Slides where the primary antibody was omitted showed no labeling and served as negative controls.

\section{Visualization and quantification}

Slide sections and whole mounts were visualized using an epifluorescence microscope (BX51, Olympus) equipped with filters for FITC and AF546, with images acquired by a CoolSnap $f x$ monochrome digital camera (Roper Scientific). Pseudocolored fluorescence and differential interference contrast (DIC) images were overlaid and fluorescence imaging software (analysis LifeScience, Olympus) used to calculate the percentage of complete traced and labeled nodose ganglia neurons, counted in 6-8 whole ganglion profiles representative of the rostrocaudal extent of each ganglion; cell fragments were ignored. Luminance of images was not adjusted.

\section{Statistical analysis}

Differences in the proportion of vagal afferents innervating gastric muscle and mucosa, and labeled for nNOS, were assessed using an unpaired $t$ test. A $p$ value of $<0.05$ was considered significant, and results are expressed as the mean \pm SEM of the number of animals $(n)$.

\section{Results}

Endogenous nitric oxide modulates vagal afferent mechanosensitivity In the ferret, inhibition of NOS with L-NAME $(100 \mu \mathrm{M})$ significantly enhanced the response of mucosal receptors in vitro to mucosal stroking with calibrated von Frey hairs $(10-200 \mathrm{mg}, p<0.01)$ (Fig. $1 A)$. The effect of L-NAME $(100 \mu \mathrm{M})$ was reversed by the addition of the NOS substrate L-arginine $(100 \mu \mathrm{M}$, $p<0.01$ ) (Fig. $1 A$ ). This effect of L-NAME on mucosal receptors was selective, because L-NAME did not affect the response of tension or tension/mucosal receptors to circular tension (Fig. $1 \mathrm{~B}, \mathrm{Cii}$ ), or the response of tension/mucosal receptors to mucosal stroking (Fig. 1Ci).

The effect of L-NAME on mouse mucosal and tension receptor sensitivity to mechanical stimulation (Fig. 2) was comparable with that in ferret. L-NAME $(100 \mu \mathrm{M})$ significantly enhanced the 


\section{Mouse gastroesophageal mucosal receptors}

A) eNOS inhibitor L-NIO

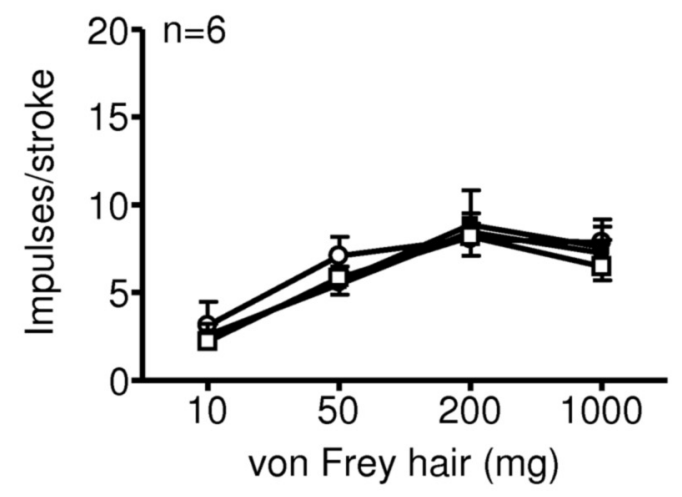

\section{B) nNOS inhibitor N-PLA}

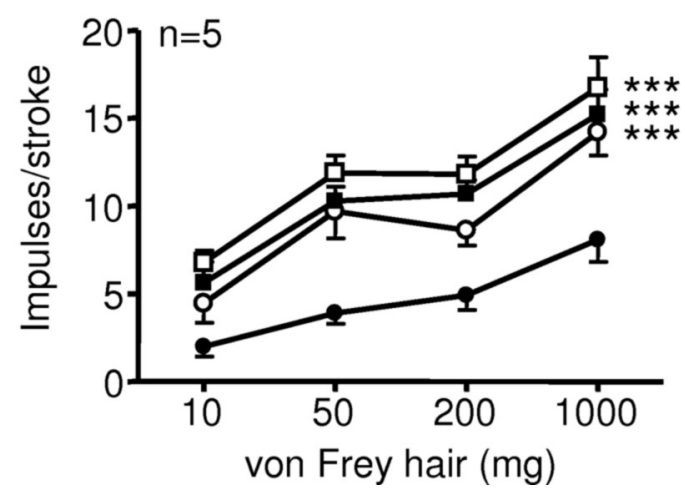

Figure 3. Effects of selective nitric oxide synthase inhibitors on mouse gastroesophageal vagal afferent mucosal receptors. Stimulus-response functions of mucosal receptors to mucosal stroking with calibrated von Frey hairs. The responses are before $(\boldsymbol{O})$ and after exposure to $N^{5}$-(1-Iminoethyl)-L-ornithine dihydrochloride $(\boldsymbol{A} ; \bigcirc, 1 \mu \mathrm{m} ; \mathbf{\square}, 3 \mu \mathrm{m} ; \square, 10 \mu \mathrm{m})$ and $N^{\omega_{-}}$ propyl---arginine $(\boldsymbol{B} ; \bigcirc, 0.1 \mu \mathrm{m} ; \mathbf{\square}, 0.3 \mu \mathrm{m} ; \square, 1 \mu \mathrm{M})$. ${ }^{* *}$ Significant difference from control curve using a two-way ANOVA $(p<0.001)$.

response of mouse mucosal receptors to mucosal stroking (10$1000 \mathrm{mg}, p<0.001$ ) (Fig. $2 \mathrm{~A}, \mathrm{Cii}$ ). This effect was significantly reversed by the addition of $\mathrm{L}$-arginine $(100 \mu \mathrm{M}, p<0.001)$ (Fig. 2A, Ciii).

To determine the likely source of NO involved, we tested the effect of selective NOS inhibitors on mouse mucosal receptor responses. L-NIO $(1-10 \mu \mathrm{M})$, the eNOS inhibitor, had no significant effect, whereas N-PLA $(0.1-1 \mu \mathrm{M})$, the nNOS inhibitor, significantly and dose-dependently enhanced their responses $(p<0.001)$ (Fig. 3B).

Mechanism of action of nitric oxide

Our experiments using NOS inhibitors suggested an inhibitory effect of $\mathrm{NO}$ on afferent sensitivity. This was assessed by exogenous NO administration using the NO donor SNAP on mouse mucosal and tension receptors. SNAP (3-30 $\mu \mathrm{M})$ significantly and dose-dependently reduced the responses of both populations (Fig. 4).

One of the major targets for NO in neurons is soluble guanylate cyclase, resulting in accumulation of cGMP. We determined whether inhibition of cGMP breakdown using the phosphodiesterase $5^{\prime}$ inhibitor sildenafil mimicked $\mathrm{NO}$ effects on mouse mu-

\section{Mouse gastroesophageal vagal afferents}

A) Mucosal

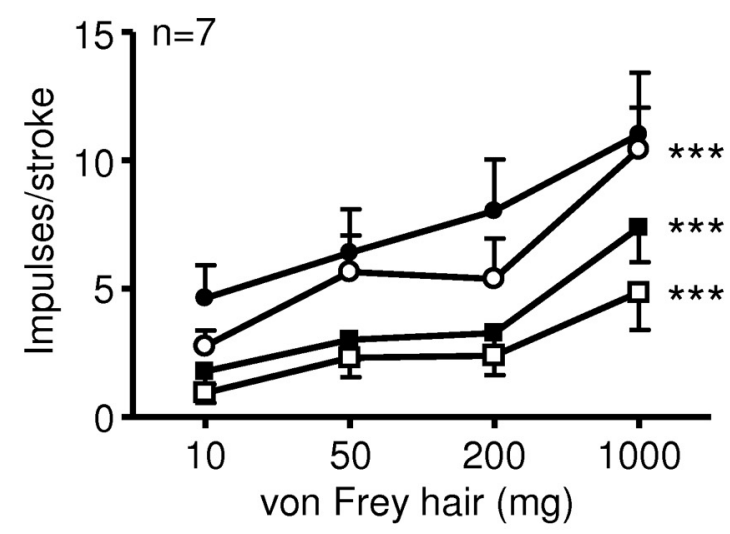

\section{B) Tension}

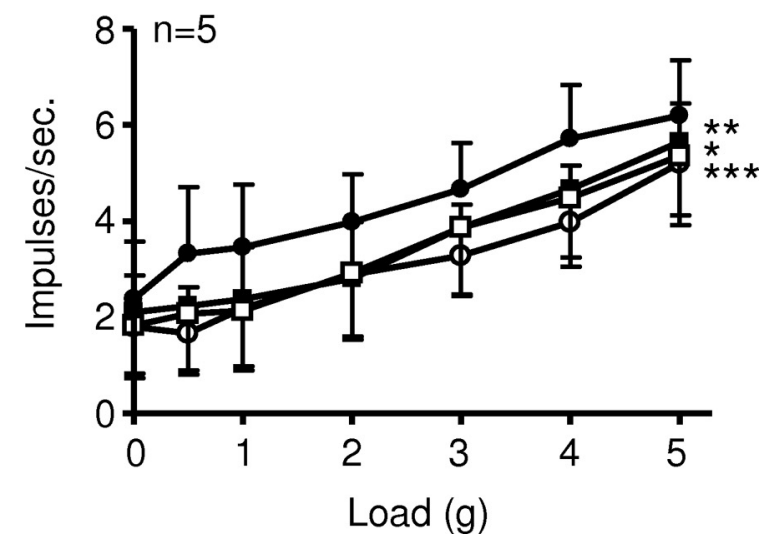

Figure 4. The nitric oxide donor SNAP inhibits mouse gastroesophageal vagal afferents. $\boldsymbol{A}$, $\boldsymbol{B}$, Stimulus-response functions of mucosal $(\boldsymbol{A})$ and tension $(\boldsymbol{B})$ receptors to mucosal stroking with calibrated von Frey hairs and circumferential tension, respectively. The responses are before $(\bigcirc)$ and after $(\bigcirc)$ exposure to $\operatorname{SNAP}(\bigcirc, 3 \mu \mathrm{m} ; \mathbf{\square}, 10 \mu \mathrm{m} ; \square, 30 \mu \mathrm{m}) .{ }^{*} p<0.05,{ }^{* *} p<$ $0.01,{ }^{* *} p<0.001$, significant difference from control curve using a two-way ANOVA.

cosal receptors. Sildenafil (10-100 nM) significantly and dosedependently reduced the stimulus-response functions of mucosal receptors $(p<0.001)$ (Fig. $5 A, C)$. We also determined the effect of inhibiting NO-sensitive soluble guanylyl cyclase with ODQ on mucosal receptor function. ODQ (1-10 $\mu \mathrm{M})$ significantly and dose-dependently enhanced the stimulus-response functions of mucosal receptors $(p<0.0001)$ (Fig. 5B).

Localization of NOS in vagal afferent pathways

Having shown that endogenous NO has inhibitory effects on afferent endings, we investigated its likely source anatomically. First we tested the hypothesis that NO was derived from the afferents themselves using neuronal tracing and immunohistochemistry. Tracing from gastric muscle with injections of CTBAF555 resulted in bright cytoplasmic labeling of $9 \pm 1$ of cell bodies within the nodose ganglia; tracing from gastric mucosa labeled $7 \pm 1 \%$ (Fig. $6 A, D$ ). In the whole nodose ganglia, $10 \pm$ $1 \%$ of cell bodies were positive for nNOS (Fig. $6 B, D$ ), whereas $27 \pm 3 \%$ and $33 \pm 1 \%$ of neurons traced from gastric muscle and mucosa, respectively, were nNOS positive (Fig. 6C,F,G). The proportion of cell bodies immunoreactive for nNOS was significantly greater in the gastric muscular and mucosal populations 


\section{Mouse gastroesophageal mucosal receptors}

A

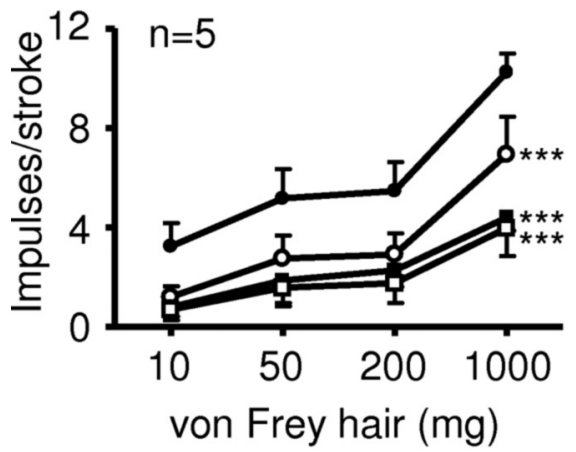

B

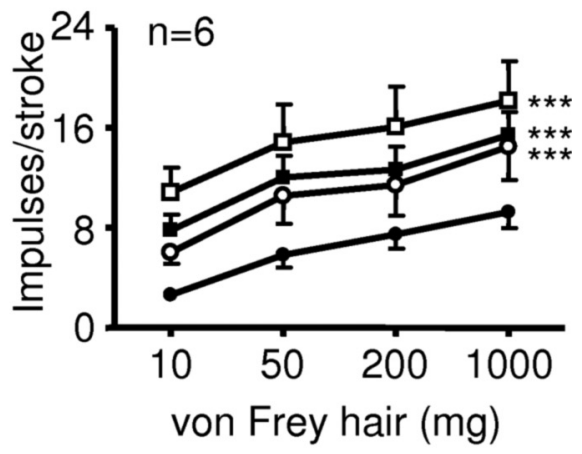

C

(i) Control

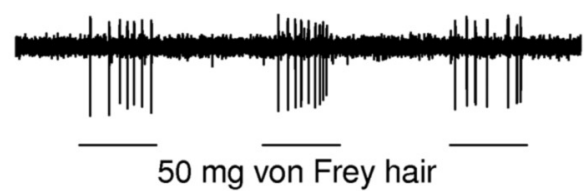

(ii)Sildenafil (10 nM)

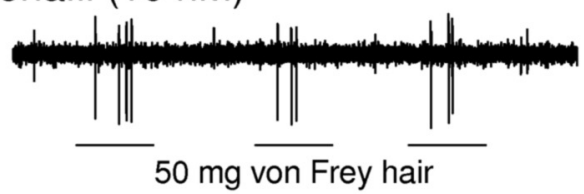

(iii) Sildenafil $(30 \mathrm{nM})$

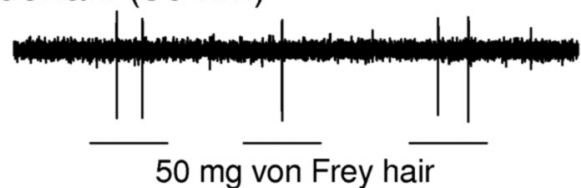

(iv) Sildenafil $(100 \mathrm{nM})$
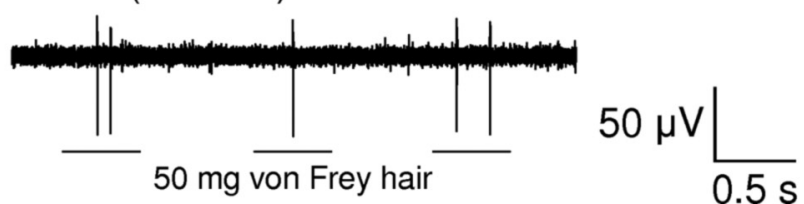

Figure 5. Interfering with the NO- CGMP pathway. $A, B$, Stimulus-response functions of mucosal receptors to mucosal stroking with calibrated von Frey hairs. The responses are before $(\boldsymbol{O})$ and after $(\bigcirc)$ exposure to sildenafil $(\boldsymbol{A})(\bigcirc, 10 \mathrm{~nm} ; \boldsymbol{\square}, 30 \mathrm{~nm} ; \square$, $100 \mathrm{~nm})$ and $\mathrm{ODQ}(\boldsymbol{B})(\bigcirc, 1 \mu \mathrm{m} ; \boldsymbol{\square}, 3 \mu \mathrm{m} ; \square, 10 \mu \mathrm{M})$. ${ }^{* * *}$ Significant difference from control curve using a two-way ANOVA ( $p<$ 0.001). C, Original recording of a mucosal receptor response to stroking with a $50 \mathrm{mg}$ von Frey hair before (i) and after (ii, $10 \mathrm{~nm}$; iii, $30 \mathrm{~nm} ; \boldsymbol{i v}, 100 \mathrm{~nm})$ exposure to sildenafil.

than in the whole ganglia ( $p<0.0001$, unpaired $t$ test) (Fig. 6G), suggesting that they may be a significant source of peripheral NO.

We investigated whether or not the nNOS found in nodose neurons is transported to their peripheral endings using anterograde tracing and immunohistochemistry. Vagal afferent endings anterogradely traced from the nodose ganglia are illustrated in Figure 7, $A$ and $D$. Identified vagal afferent endings observed during the present investigation were immunonegative for nNOS. However, as expected, cell bodies and fibers of the myenteric plexus were strongly immunoreactive for nNOS (Fig. $7 B$ ), and vagal afferent axons and nerve endings often enveloped the myenteric ganglia, forming intraganglionic laminar endings (IGLEs), but did not appear to penetrate them, and no double label was seen (Fig. 7C). Isolated cells in the stomach submucosal gland were strongly immunoreactive for nNOS (Fig. $7 E$ ), and had morphology consistent with enteroendocrine cells. Anterogradely traced vagal afferent fibers penetrating the mucosal layer of the stomach were found closely apposed within a few micrometers of these cells (Fig. 7F).

\section{Discussion}

We have demonstrated that endogenous NO inhibits mechanosensory function in a subpopulation of primary sensory endings. Inhibition of NO production potentiated the response of gut mucosal receptors in two widely different mammalian species-mice and ferrets, in some cases severalfold. This effect was mimicked by a nNOS inhibitor but not an eNOS inhibitor, suggesting that the $\mathrm{NO}$ is neuronal or enteroendocrine in origin. Another consistent finding was that effects of NOS inhibition were confined to mucosal endings, with no effect on muscular endings, providing further clues as to the anatomical source of NO. Neuroanatomical tracing and immunohistochemistry confirmed a mucosal source of NOS within enteroendocrine cells close to vagal terminals. The afferent endings themselves were unlikely as a source, since they were nNOS negative, even though their cell bodies produce the enzyme. We confirmed that intrinsic myenteric neurons are also a potential source of NO. However, tension receptors, which terminate in IGLEs surrounding myenteric ganglia, did not penetrate them, and were correspondingly unaffected by blockade of endogenous NOS. The NO donor SNAP reduced the response of both mucosal and tension receptors to mechanical stimulation. Therefore, although endogenous NO is not available at tension receptor endings, exogenous NO can influence their mechanosensitivity. Its mechanism of action on vagal afferents is likely via the arginine-NOcGMP pathway, since sildenafil, a specific inhibitor of cGMP phosphodiesterase, and thus a stimulator of the cGMP pathway, mimicked the effects of the NO donor. This is supported by the fact that inhibition of NO-sensitive guanylyl cyclase with ODQ had the opposite effect.

Our data support a model of nitric oxide derived from gut mucosal cells exerting an inhibitory influence on nearby vagal afferent endings. Distension of the stomach is sufficient to increase luminal NO release (Ito et al., 2008), which would be derived from mucosal cells, and luminal contact is also well established as a stimulus for enteroendocrine cell degranulation leading to activation of sensory neurons (Kirchgessner et al., 1992; Kim et al., 2001). Therefore there are several physiological circumstances in which this process would be active. It is conceiv- 
able that NO release mitigates the neural actions of excitatory transmitters and modulators coreleased from the gut mucosa in response to meals such as 5-HT and CCK (Blackshaw and Grundy, 1993a,b; Grundy et al., 1994; Lal et al., 2001), which might otherwise mediate undampened activation of vagal afferents and behavioral consequences such as nausea and vomiting after a normal meal. A question that arises from our study is whether NO is continually released from the mucosa or only during mechanical stimulation by stroking. Evidence from previous studies indicates that NO is released by specific mechanical or neural stimuli (King et al., 2003; Ito et al., 2008), suggesting the latter.

In addition to the gastrointestinal tract, there are numerous areas within the body where similar epithelial-to-neuronal communication processes exist. A prime example is the bladder urothelium and adjacent subepithelial nerve supply (Birder, 2005), where nerve fibers are in close proximity to cells in the urothelium that contain transmitters, which can be released and influence the activity of subepithelial nerves. Although actions of nitric oxide on sensory endings have been shown elsewhere in the body, on articular, dural, or cutaneous sensory nerves, the endogenous source is not clear, but would obviously be from a different cell type than that in the gut. In these, NO can either enhance or decrease the responsiveness of endings to either chemical or mechanical stimuli depending on the location, the specific subset of nerves concerned, or even the inflammatory status (Kelly et al., 2001; Vivancos et al., 2003; Levy and Strassman, 2004). In contrast, in the present study NO reproducibly inhibited the response of both types of gastroesophageal vagal afferents, suggesting that the downstream mechanism is more consistent.

We found $10 \%$ of nodose ganglion neurons were positive for $\mathrm{nNOS}$. The proportion of gastric-projecting cell bodies immunoreactive for nNOS was three times greater than in the whole ganglion, indicating a degree of specificity of nNOS for gastric afferents, but not in individual subtypes of gastric afferents. Our data indicate that nodose nNOS is not transported to the stomach, because peripheral endings of vagal afferents were nNOS negative. This corroborates tracing data from the rat, in which peripheral vagal afferent terminals in the esophagus were NOS negative (Dütsch et al., 1998), as are those in rat lung (Brouns et al., 2002). Therefore, although nNOS is three times more likely to be expressed in gastric neurons compared with the general vagal afferent population, this is not transported to the peripheral endings and is therefore unlikely to be responsible for the generation of NO involved in modulating afferent mechanosensitivity. Vagal afferent NOS is also unlikely to be involved in central neurotransmis-

G
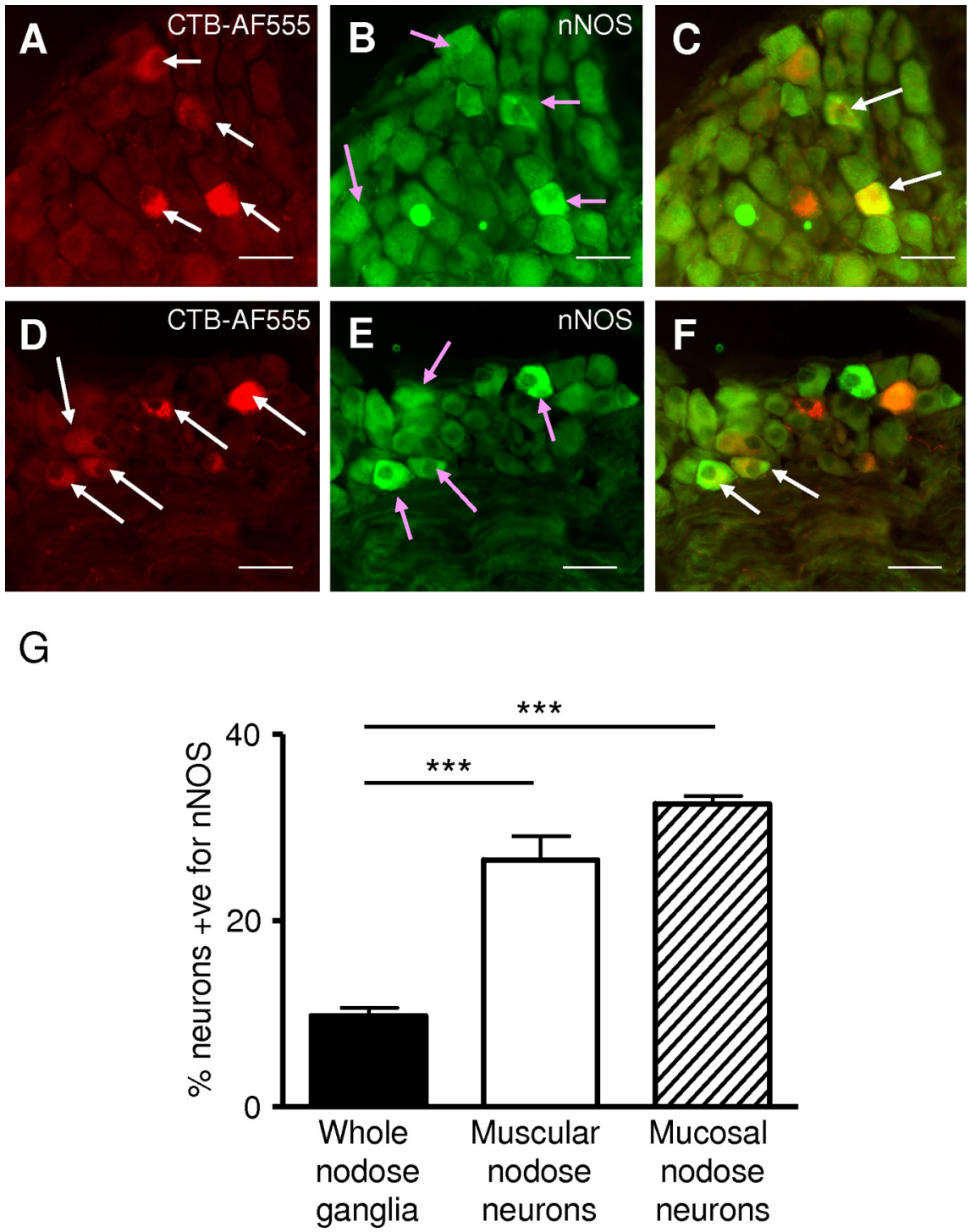

Figure 6. Combined nNOS immunohistochemistry and retrograde tracing in the mouse nodose ganglia. $\boldsymbol{A}$, Mouse nodose ganglia showing retrogradely traced (CTB-AF555) gastric mucosal afferent neurons (red; indicated by the white arrows). $\boldsymbol{B}$ Neurons immunoreactive for nNOS (green; indicated by pink arrows). C, nNOS immunoreactivity (green) and colabel (yellow; indicated by white arrow). Two gastric mucosal afferents are seen prominently colabeled with nNOS (indicated by white arrows). $\boldsymbol{D}$, Retrogradely traced (CTB-AF555) gastric muscular afferent neurons (red; indicated by white arrows). $\boldsymbol{E}$, Neurons immunoreacTwo gastric muscular afferents are prominently colabeled with nNOS (indicated by white arrow). Scale bars, $150 \mu \mathrm{m}$. G, The percentage of neurons in the nodose ganglia immunoreactive for nNOS. The percentage of neurons immunoreactive for nNOS in the whole nodose ganglia is significantly less $\left(^{* * *} p<0.001\right.$; unpaired $t$ test) than the percentage of both gastric mucosal and muscular afferent neurons immunoreactive for nNOS.

sion, since it is not transported to central terminals (Atkinson et al., 2003), although again it was detected in the nodose ganglion. Therefore NOS may be more important in metabolic and antiapoptotic processes within the nodose ganglion cell body, as is found in dorsal root ganglion neurons (Thippeswamy and Morris, 2002).

Immunohistochemistry for nNOS in the mouse stomach confirmed that there is an abundance of myenteric neurons and their processes that are immunopositive for nNOS, supporting previous literature (Grozdanovic et al., 1992; Neuhuber et al., 1994; Raab and Neuhuber, 2004). We found vagal afferent fibers, traced from the nodose ganglia, formed IGLEs surrounding myenteric ganglia containing nNOS-immunopositive neurons. Although 

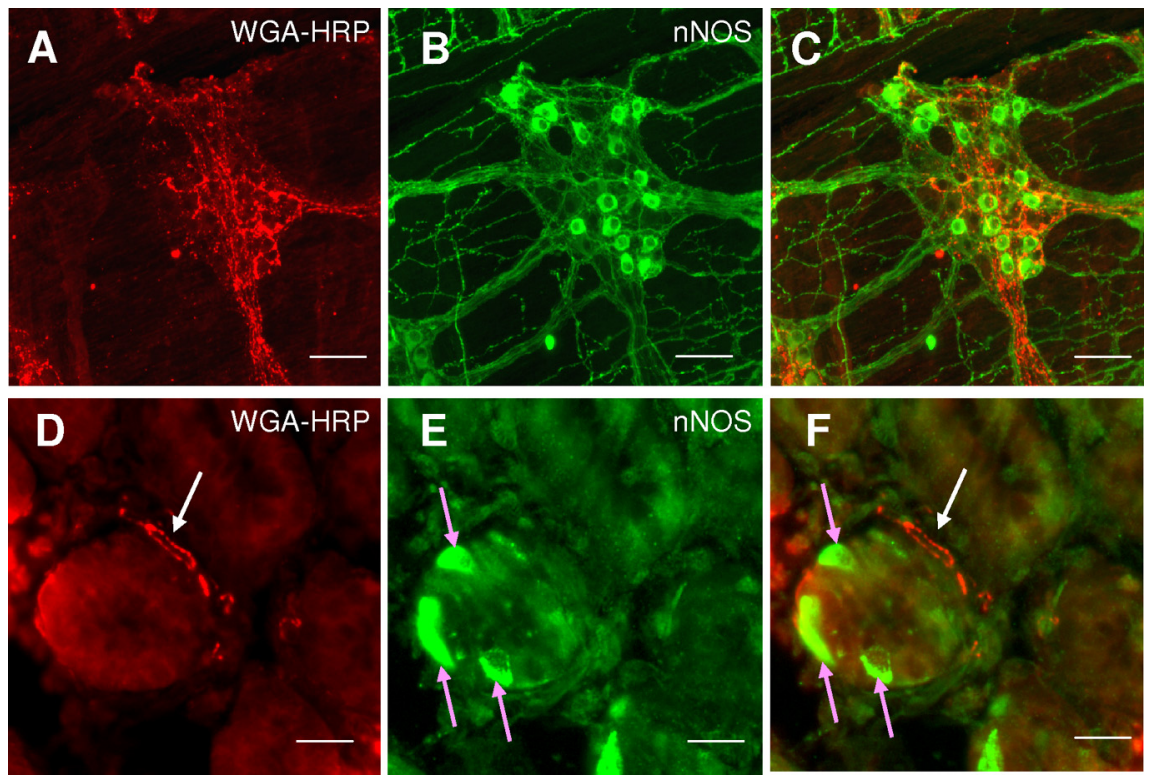

Figure 7. Combined nNOS immunohistochemistry and anterogradely traced vagal afferent fibers in the mouse stomach. $\boldsymbol{A}-\boldsymbol{C}$, Whole-mount mouse stomach longitudinal muscle and myenteric plexus. $\boldsymbol{A}$, Anterogradely traced (WGA-HRP) vagal afferent fibers. $\boldsymbol{B}, \mathrm{nNOS}$-labeled fibers and cell bodies in the myenteric plexus. $\boldsymbol{C}$, Overlay of $\boldsymbol{A}$ and $\boldsymbol{B}$ showing close proximity of nNOScontaining fibers to anterograde labeled vagal afferent fibers but not colocalization. Scale bars, $250 \mu \mathrm{m}$. D-F, Stomach sections showing a cross section through a gland. $\boldsymbol{D}$, Anterogradely traced (WGA-HRP) vagal afferent fiber. $\boldsymbol{E}$, Epithelial cells immunopositive for nNOS in stomach villi. $\boldsymbol{F}, 0$ verlay of $\boldsymbol{D}$ and $\boldsymbol{E}$ showing close proximity of $n N O S$-containing epithelial cells (indicated by pink arrows) and anterograde labeled vagal afferent fibers (indicated by white arrow). Scale bars, $75 \mu \mathrm{m}$.

IGLEs are the mechanotransduction sites of vagal tension receptors (Zagorodnyuk and Brookes, 2000; Zagorodnyuk et al., 2003), the nNOS inhibitor did not affect their mechanosensitivity. Therefore, the NO produced by myenteric neurons does not reach IGLEs surrounding them at sufficient concentrations. This is possibly due to a diffusion barrier provided by the collagenase that surrounds bundles of myenteric neurons (Gabella, 1972; Rodrigues de Souza et al., 1988), and the characteristic rapid degradation of NO (Cary et al., 2006).

Immunoreactivity for nNOS was detected in a distinct subpopulation of cells within the gastric mucosa. Neuronal nitric oxide synthase has been detected within several different types of cells of the gastrointestinal mucosa, such as the epithelium of the rat forestomach (Schmidt et al., 1992), brush cells (Kugler et al., 1994), chief cells (Fiorucci et al., 1995), and some endocrine cells (Burrell et al., 1996) and mucosecretory cells (Brown et al., 1992; Price et al., 1996; Byrne et al., 1997; Ichikawa et al., 1998; Price and Hanson, 1998). Preliminary studies investigating eNOS immunoreactivity in the gastric mucosa agree with previous reports on eNOS immunoreactivity in the rat stomach (Price et al., 1996), indicating that although eNOS was present in blood vessels penetrating the submucosa, the specialized gastric epithelial cells were eNOS negative (data not shown). It is clear from the present investigation that vagal afferent endings can be found in very close proximity to these nNOS-containing cells in the gastric mucosa; this provides an anatomical correlate of our evidence for NO released from the mucosa influencing the mechanosensitivity of mucosal vagal afferents. There is no diffusion barrier within the lamina propria, preventing NO from acting on these afferents, as is the case with IGLEs and myenteric neurons.

One of the main signal transduction pathways for NO occurs through formation of a complex with soluble guanylate cyclase, which activates the enzyme to catalyze the conversion of GTP to cGMP and pyrophosphate. cGMP then binds to various target likely to modulate symptoms, behavioral responses, and vagal reflexes from the upper gastrointestinal system.

\section{References}

Alderton WK, Cooper CE, Knowles RG (2001) Nitric oxide synthases: structure, function and inhibition. Biochem J 357:593-615.

Andrews PL, Sanger GJ (2002) Abdominal vagal afferent neurones: an important target for the treatment of gastrointestinal dysfunction. Curr Opin Pharmacol 2:650-656.

Atkinson L, Batten TF, Corbett EK, Sinfield JK, Deuchars J (2003) Subcellular localization of neuronal nitric oxide synthase in the rat nucleus of the solitary tract in relation to vagal afferent inputs. Neuroscience 118:115-122.

Bielefeldt K, Whiteis CA, Chapleau MW, Abboud FM (1999) Nitric oxide enhances slow inactivation of voltage-dependent sodium currents in rat nodose neurons. Neurosci Lett 271:159-162.

Birder LA (2005) More than just a barrier: urothelium as a drug target for urinary bladder pain. Am J Physiol Renal Physiol 289:F489-F495.

Blackshaw LA (2001) Receptors and transmission in the brain-gut axis: potential for novel therapies. IV. GABA(B) receptors in the braingastroesophageal axis. Am J Physiol Gastrointest Liver Physiol 281:G311-G315.

Blackshaw LA, Grundy D (1993a) Effects of 5-hydroxytryptamine on discharge of vagal mucosal afferent fibres from the upper gastrointestinal tract of the ferret. J Auton Nerv Syst 45:41-50.

Blackshaw LA, Grundy D (1993b) Effects of 5-hydroxytryptamine (5-HT) on the discharge of vagal mechanoreceptors and motility in the upper gastrointestinal tract of the ferret. J Auton Nerv Syst 45:51-59.

Blackshaw LA, Gebhart GF (2002) The pharmacology of gastrointestinal nociceptive pathways. Curr Opin Pharmacol 2:642-649.

Boeckxstaens GE, Pelckmans PA, Bogers JJ, Bult H, De Man JG, Oosterbosch L, Herman AG, Van Maercke YM (1991) Release of nitric oxide upon stimulation of nonadrenergic noncholinergic nerves in the rat gastric fundus. J Pharmacol Exp Ther 256:441-447.

Bredt DS, Snyder SH (1992) Nitric oxide, a novel neuronal messenger. Neuron 8:3-11.

Bredt DS, Hwang PM, Snyder SH (1990) Localization of nitric oxide synthase indicating a neural role for nitric oxide. Nature 347:768-770.

Brouns I, Van Genechten J, Scheuermann DW, Timmermans JP, Adriaensen 
D (2002) Neuroepithelial bodies: a morphologic substrate for the link between neuronal nitric oxide and sensitivity to airway hypoxia? J Comp Neurol 449:343-354.

Brown JF, Tepperman BL, Hanson PJ, Whittle BJ, Moncada S (1992) Differential distribution of nitric oxide synthase between cell fractions isolated from the rat gastric mucosa. Biochem Biophys Res Commun 184:680-685.

Bult H, Boeckxstaens GE, Pelckmans PA, Jordaens FH, Van Maercke YM, Herman AG (1990) Nitric oxide as an inhibitory non-adrenergic noncholinergic neurotransmitter. Nature 345:346-347.

Burrell MA, Montuenga LM, García M, Villaro AC (1996) Detection of nitric oxide synthase (NOS) in somatostatin-producing cells of human and murine stomach and pancreas. J Histochem Cytochem 44:339-346.

Byrne CR, Price KJ, Williams JM, Brown JF, Hanson PJ, Whittle BJ (1997) Nitric oxide synthase and arginase in cells isolated from the rat gastric mucosa. Biochim Biophys Acta 1356:131-139.

Cary SP, Winger JA, Derbyshire ER, Marletta MA (2006) Nitric oxide signaling: no longer simply on or off. Trends Biochem Sci 31:231-239.

D'Amato M, Currò D, Montuschi P (1992) Evidence for dual components in the non-adrenergic non-cholinergic relaxation in the rat gastric fundus: role of endogenous nitric oxide and vasoactive intestinal polypeptide. J Auton Nerv Syst 37:175-186.

Dütsch M, Eichhorn U, Wörl J, Wank M, Berthoud HR, Neuhuber WL (1998) Vagal and spinal afferent innervation of the rat esophagus: a combined retrograde tracing and immunocytochemical study with special emphasis on calcium-binding proteins. J Comp Neurol 398:289-307.

Fiorucci S, Distrutti E, Santucci L, Morelli A (1995) Leukotrienes stimulate pepsinogen secretion from guinea pig gastric chief cells by a nitric oxidedependent pathway. Gastroenterology 108:1709-1719.

Fornai M, Colucci R, Antonioli L, Baschiera F, Ghisu N, Tuccori M, Gori G, Blandizzi C, Del Tacca M (2007a) CCK2 receptors mediate inhibitory effects of cholecystokinin on the motor activity of guinea-pig distal colon. Eur J Pharmacol 557:212-220.

Fornai M, Colucci R, Antonioli L, Crema F, Buccianti P, Chiarugi M, Baschiera F, Ghisu N, Tuccori M, Blandizzi C, Del Tacca M (2007b) Cholecystokinin CCK2 receptors mediate the peptide's inhibitory actions on the contractile activity of human distal colon via the nitric oxide pathway. Br J Pharmacol 151:1246-1253.

Furchgott RF, Zawadzki JV (1980) The obligatory role of endothelial cells in the relaxation of arterial smooth muscle by acetylcholine. Nature 288:373-376.

Gabella G (1972) Fine structure of the myenteric plexus in the guinea-pig ileum. J Anat 111:69-97.

García-Vitoria M, García-Corchón C, Rodríguez JA, García-Amigot F, Burrell MA (2000) Expression of neuronal nitric oxide synthase in several cell types of the rat gastric epithelium. J Histochem Cytochem 48:1111-1120.

Garthwaite J, Boulton CL (1995) Nitric oxide signaling in the central nervous system. Annu Rev Physiol 57:683-706.

Garthwaite J, Charles SL, Chess-Williams R (1988) Endothelium-derived relaxing factor release on activation of NMDA receptors suggests role as intercellular messenger in the brain. Nature 336:385-388.

Grozdanovic Z, Baumgarten HG, Brüning G (1992) Histochemistry of NADPH-diaphorase, a marker for neuronal nitric oxide synthase, in the peripheral autonomic nervous system of the mouse. Neuroscience 48:225-235.

Grundy D, Blackshaw LA, Hillsley K (1994) Role of 5-hydroxytryptamine in gastrointestinal chemosensitivity. Dig Dis Sci 39:44S-47S.

Gumusel B, Hao Q, Hyman AL, Kadowitz PJ, Champion HC, Chang JK, Mehta JL, Lippton H (1998) Analysis of responses to adrenomedullin(13-52) in the pulmonary vascular bed of rats. Am J Physiol 274:H1255-H1263.

Ichikawa T, Ishihara K, Kusakabe T, Kurihara M, Kawakami T, Takenaka T, Saigenji K, Hotta K (1998) Distinct effects of tetragastrin, histamine, and $\mathrm{CCh}$ on rat gastric mucin synthesis and contribution of NO. Am J Physiol 274:G138-146.

Ito Y, Okuda S, Ohkawa F, Kato S, Mitsufuji S, Yoshikawa T, Takeuchi K (2008) Dual role of nitric oxide in gastric hypersecretion in the distended stomach: inhibition of acid secretion and stimulation of pepsinongen secretion. Life Sci 83:886-892.

Jacoby S, Sims RE, Hartell NA (2001) Nitric oxide is required for the induc- tion and heterosynaptic spread of long-term potentiation in rat cerebellar slices. J Physiol 535:825-839.

Kelly DC, Asghar AU, Marr CG, McQueen DS (2001) Nitric oxide modulates articular sensory discharge and responsiveness to bradykinin in normal and arthritic rats in vivo. Neuroreport 12:121-125.

Kim M, Javed NH, Yu JG, Christofi F, Cooke HJ (2001) Mechanical stimulation activates Galphaq signaling pathways and 5-hydroxytryptamine release from human carcinoid BON cells. J Clin Invest 108:1051-1059.

King BN, Haque SM, Stoner MC, Ellis ZM, Kellum JM (2003) Inhibition of neural nitric oxide synthase attenuates the chloride secretory response to stroking in human jejunum. Surgery 134:255-259.

Kirchgessner AL, Tamir H, Gershon MD (1992) Identification and stimulation by serotonin of intrinsic sensory neurons of the submucosal plexus of the guinea pig gut: activity-induced expression of Fos immunoreactivity. J Neurosci 12:235-248.

Kugler P, Höfer D, Mayer B, Drenckhahn D (1994) Nitric oxide synthase and NADP-linked glucose-6-phosphate dehydrogenase are co-localized in brush cells of rat stomach and pancreas. J Histochem Cytochem 42:1317-1321.

Lal S, Kirkup AJ, Brunsden AM, Thompson DG, Grundy D (2001) Vagal afferent responses to fatty acids of different chain length in the rat. Am J Physiol Gastrointest Liver Physiol 281:G907-G915.

Lev-Ram V, Wong ST, Storm DR, Tsien RY (2002) A new form of cerebellar long-term potentiation is postsynaptic and depends on nitric oxide but not cAMP. Proc Natl Acad Sci U S A 99:8389-8393.

Levy D, Strassman AM (2004) Modulation of dural nociceptor mechanosensitivity by the nitric oxide-cyclic GMP signaling cascade. J Neurophysiol 92:766-772.

Moncada S (1992) The 1991 Ulf von Euler Lecture. The L-arginine: nitric oxide pathway. Acta Physiol Scand 145:201-227.

Morley JE, Farr SA, Suarez MD, Flood JF (1995) Nitric oxide synthase inhibition and food intake: effects on motivation to eat and in female mice. Pharmacol Biochem Behav 50:369-373.

Neuhuber WL, Wörl J, Berthoud HR, Conte B (1994) NADPH-diaphorasepositive nerve fibers associated with motor endplates in the rat esophagus: new evidence for co-innervation of striated muscle by enteric neurons. Cell Tissue Res 276:23-30.

Page AJ, Blackshaw LA (1998) An in vitro study of the properties of vagal afferent fibres innervating the ferret oesophagus and stomach. J Physiol 512:907-916.

Page AJ, Blackshaw LA (1999) GABA $_{\mathrm{B}}$ receptors inhibit mechanosensitivity of primary afferent endings. J Neurosci 19:8597-8602.

Page AJ, Martin CM, Blackshaw LA (2002) Vagal mechanoreceptors and chemoreceptors in mouse stomach and esophagus. J Neurophysiol 87:2095-2103.

Page AJ, O’Donnell TA, Blackshaw LA (2006) Inhibition of mechanosensitivity in visceral primary afferents by GABAB receptors involves calcium and potassium channels. Neuroscience 137:627-636.

Page AJ, Slattery JA, O’Donnell TA, Cooper NJ, Young RL, Blackshaw LA (2005a) Modulation of gastro-oesophageal vagal afferents by galanin in mouse and ferret. J Physiol 563:809-819.

Page AJ, Young RL, Martin CM, Umaerus M, O’Donnell TA, Cooper NJ, Coldwell JR, Hulander M, Mattsson JP, Lehmann A, Blackshaw LA (2005b) Metabotropic glutamate receptors inhibit mechanosensitivity in vagal sensory neurons. Gastroenterology 128:402-410.

Palmer RM, Ferrige AG, Moncada S (1987) Nitric oxide release accounts for the biological activity of endothelium-derived relaxing factor. Nature 327:524-526.

Price K, Hanson P (1998) Constitutive nitric oxide synthases in rat gastric mucosa: subcellular distribution, relative activity and different carboxylterminal antigenicity of the neuronal form compared with cerebellum. Digestion 59:308-313.

Price KJ, Hanson PJ, Whittle BJ (1996) Localization of constitutive isoforms of nitric oxide synthase in the gastric glandular mucosa of the rat. Cell Tissue Res 285:157-163.

Raab M, Neuhuber WL (2004) Intraganglionic laminar endings and their relationships with neuronal and glial structures of myenteric ganglia in the esophagus of rat and mouse. Histochem Cell Biol 122:445-459.

Renganathan M, Cummins TR, Waxman SG (2002) Nitric oxide blocks fast, slow, and persistent $\mathrm{Na}+$ channels in C-type DRG neurons by S-nitrosylation. J Neurophysiol 87:761-775. 
Robinson PH, Clarke M, Barrett J (1988) Determinants of delayed gastric emptying in anorexia nervosa and bulimia nervosa. Gut 29:458-464.

Rodrigues de Souza R, Ferraz de Carvalho CA, Watanabe I (1988) Identification of collagen, elastic, elaunin and oxytalan fibres in ganglia of the myenteric plexus of the human oesophagus. Anat Embryol (Berl) 179:97-102.

Schmidt HH, Gagne GD, Nakane M, Pollock JS, Miller MF, Murad F (1992) Mapping of neural nitric oxide synthase in the rat suggests frequent colocalization with NADPH diaphorase but not with soluble guanylyl cyclase, and novel paraneural functions for nitrinergic signal transduction. J Histochem Cytochem 40:1439-1456.

Tack J, Caenepeel P, Corsetti M, Janssens J (2004) Role of tension receptors in dyspeptic patients with hypersensitivity to gastric distention. Gastroenterology 127:1058-1066.

Thippeswamy T, Morris R (2002) The roles of nitric oxide in dorsal root ganglion neurons. Ann N Y Acad Sci 962:103-110.

Vivancos GG, Parada CA, Ferreira SH (2003) Opposite nociceptive effects of the arginine/NO/cGMP pathway stimulation in dermal and subcutaneous tissues. Br J Pharmacol 138:1351-1357.

Xie QW, Cho HJ, Calaycay J, Mumford RA, Swiderek KM, Lee TD, Ding A, Troso T, Nathan C (1992) Cloning and characterization of inducible nitric oxide synthase from mouse macrophages. Science 256:225-228.

Yamamoto Y, Henrich M, Snipes RL, Kummer W (2003) Altered production of nitric oxide and reactive oxygen species in rat nodose ganglion neurons during acute hypoxia. Brain Res 961:1-9.

Zagorodnyuk VP, Brookes SJ (2000) Transduction sites of vagal mechanoreceptors in the guinea pig esophagus. J Neurosci 20:6249-6255.

Zagorodnyuk VP, Chen BN, Costa M, Brookes SJ (2003) Mechanotransduction by intraganglionic laminar endings of vagal tension receptors in the guinea-pig oesophagus. J Physiol 553:575-587.

Zhang Q, Lehmann A, Rigda R, Dent J, Holloway RH (2002) Control of transient lower oesophageal sphincter relaxations and reflux by the $\mathrm{GABA}(\mathrm{B})$ agonist baclofen in patients with gastro-oesophageal reflux disease. Gut 50:19-24. 